\title{
Shoulder dystocia: the frightening emergencies
}

\begin{abstract}
Shoulder dystocia is a condition where there is a difficulty in the delivery of the shoulder of the fetus occurs. This is an obstetric emergency. It happens when the fetalbiacromial diameter is larger than the biparietal diameter or the maternal pelvic brim is flat rather than gynecoid, If this frightening situation is not manage properly, in time and by expert hand it can cause severe fetal and maternal outcome. All doctors should require proper training and knowledge for the management of this emergency situation. Well-trained health professionals can improve the outcome of the delivery when shoulder dystocia occurs. There is no any strong evidence to prevent shoulder dystocia because it is so unpredictable. But good control of blood glucose level of diabetic mother will reduce the incidence of macrosomic baby. Elective caesarean section is recommended for suspected fetal macrosomia to prevent brachial plexus injury.
\end{abstract}

Keywords: shoulder dystocia, brachial plexus nerve palsy, clavicle fracture, brain injury, postpartum bleeding
Volume I Issue 5 - 2015

\author{
Tahmina Afrose,' Farzana Afzal, ${ }^{2}$ Nasrin \\ Habib, ${ }^{3}$ Mamunur Rashid, ${ }^{4}$ Anath Bondhu \\ Chattopadhyay ${ }^{5}$ \\ 1.5 Department of Obstetrics \& Gynecology, AIMST University, \\ Malaysia \\ ${ }^{2}$ Department of Ophthalmology, AIMST University, Malaysia \\ ${ }^{3}$ Department of Physiology, Quest International University \\ Perak, Malaysia \\ ${ }^{4}$ Department of Medicine, Quest International University Perak, \\ Malaysia
}

Correspondence: Tahmina Afrose, Department of Obstetrics \& Gynaecology,AIMST University, Malaysia, Tel +601494026I4, Emaildrtakeya@gmail.com

Received: November 18, 2015 | Published: December 0I, 2015

\section{Introduction}

According to the definition of the Royal College of Obstetricians and Gynaecologists for shoulder dystocia some specific manoeuvres are needed for the delivery of the shoulder of the baby. ${ }^{1}$ All over the world both in developed and developing countries the incidence of this emergency situation is increasing. ${ }^{2}$ Serious feto-maternal complications are associated with the improper management of shoulder dystocia. Macrosomic baby are in high risk for the injury of the Brachial plexus in this situation. ${ }^{3,4}$ Larger infant and Shoulder dystocia are interrelated, ${ }^{5}$ but there are some evidence Shoulder dystocia can occurs in infant with less than $4000 \mathrm{gm}$ birth weight. ${ }^{6}$ Some mechanical causes are related for the development of Shoulder dystocia. ${ }^{7,8}$

\section{Risk factors for shoulder dystocia Antenatalrisk factors for shoulder dystocia are listed below}

i. Previous history of shoulder dystocia ${ }^{9}$

ii. Macrosomic baby ${ }^{10}$

iii. Gestational Diabetic mother ${ }^{11}$

iv. Obesity (body mass index $>25)^{12,13}$

v. Multiparty ${ }^{13,14}$

vi. Elderly mother ${ }^{12,13}$

\section{Intrapartum risk factors are as follows}

i. Short labour $(<20 \mathrm{~min})^{11,15}$

ii. Instrumental vaginal delivery (vacuum, forceps $)^{10}$

iii. Prolonged second stage of labour ${ }^{10}$

iv. Without local anaesthesia ( $>2 \mathrm{~h}$ for multiparous patients, or $>1 \mathrm{~h}$ for multiparous patients $)^{11}$ v. With local anaesthesia ( $>3 \mathrm{~h}$ for nulliparous patient, $>2 \mathrm{~h}$ for others) ${ }^{11}$

vi. Induction of labour for "impending macrosomia"16

In clinical practices a lot of patient having these risk factors do not face this complication but some other patient without these risk factors have the complication of shoulder dystocia. Sometimes the delivery of a small fetus can be complicated by Shoulder dystocia. ${ }^{17}$ The accurate birth weight of a macrosomic baby cannot be diagnosed before the delivery. ${ }^{16}$ Babies of diabetic mothers are in greater risk of Shoulder dystocia. ${ }^{5,18}$ Prolonged second stage of labour is also associated with Shoulder dystocia. Many of the elderly mothers having the higher BMI and there deliveries are complicated by Shoulder dystocia. ${ }^{19}$ Shoulder dystocia is also associated with multiparty because most of them are dealing with obesity. ${ }^{20}$

\section{Neonatal-maternal outcome of shoulder dystocia}

Incidence of neonatal and maternal morbidity and mortality is higher in shoulder dystocia. Prompt action can reduce this incidence. ${ }^{21}$

\section{Maternal complication of shoulder dystocia:22}

i. Hypovolumic shock due to profuse bleeding during post natal period

ii. Cervical laceration

iii. Injury to the birth canal

iv. Separation of the Pubic symphysis

v. Lateral femoral cutaneous neuropathy

vi. Rupture of the uterus

\section{Fetal complication of shoulder dystocia: 22}

i. Brachial plexus palsy 

ii. Fetal death
iii. Fetal distress
iv. Fracture of the clavicle
v. Fracture of the humerus

One dangerous neonatal complication of shoulder dystocia is Brachial Plexus nerve palsy. ${ }^{23}$ Majority of the cases resolve spontaneously. $10 \%$ of the infants with this complication may develop permanent disability. ${ }^{24}$ Either excessive traction by the doctor during the delivery or maternal bearing down effort during the labour may be the cause of this type of injury. ${ }^{25}$ Postpartum bleeding due to birth canal injury is one of the major causes of the maternal morbidity and mortality. ${ }^{26,27}$

\section{Prevention of shoulder dystocia}

If fetal weight is normal for a Gestational diabetic mother, after 38 weeks her baby can be delivered either by vaginal delivery through Induction of labour or by caesarean section. ${ }^{28}$ If the high risk mothers are identified during their antenatal period and their babies are being delivered by elective caesarean section, the incidence of Shoulder dystocia can be prevented. ${ }^{29,30}$

\section{Intrapartum management of shoulder dystocia}

For the clinical diagnosis of Shoulder dystocia during intrapartum period the health care provider should routinely observe for the followings: (Evidence level IV, RCOG) ${ }^{25}$
i. Difficulties in delivery of the face and chin
ii. "Turtle-neck sign"
iii. Failure of restitution of the fetal head
iv. There is the difficulty in descend of the shoulder

During the management of the Shoulder dystocia the birth attendants must be calm, confidant and have the ability to take prompt action. ${ }^{31}$ The mother should be needed for the counselling of this emergency situation. Documentation is always necessary. ${ }^{30}$ Systematically management of the Shoulder dystocia according to "the RCOG algorithm" may prevent some serious feto-maternal complication. ${ }^{32}$ There are various techniques for the delivery of the anterior shoulder.

\section{First-line manoeuvres: I These include}

a) Call for additional help: In this emergency situation a team work is necessary. The must have an expert obstetrician, an experienced pediatrician and an anesthetist. ${ }^{33}$

b) Discouraging fundal pressure: For the management of this type of emergency it is always suggest to avoid fundal pressure. ${ }^{34}$ Otherwise it can lead to fetal life in danger. ${ }^{35}$

c) Episiotomy: It is given when necessary. The benefit of the episiotomy is that the doctor can get more space if they try for any internal manoeuvre. ${ }^{36-39}$

d) Mcroberts' manoeuvre (Figure 1): ${ }^{37,38}$ In this type of manoeuvre maternal hips are being kept in flexed and abducted position with thighs on her abdomen. ${ }^{39}$ This manoeuvrehelp to increase the anterior-posterior diameter of the maternal pelvis creating an adequate space for the delivery of the shoulder. ${ }^{40}$ The success rates is high in this manoeuvre. ${ }^{41-44}$

e) Suprapubic pressure: Both suprapubic pressure and the
'McRoberts' manoeuvre'can be tried simultaneously. ${ }^{41}$ By applying suprapubic pressure the fetal biacromial diameter is reduced, facilitatingthe rotation of the anterior shoulder of the fetus into the wider pelvis. ${ }^{43}$

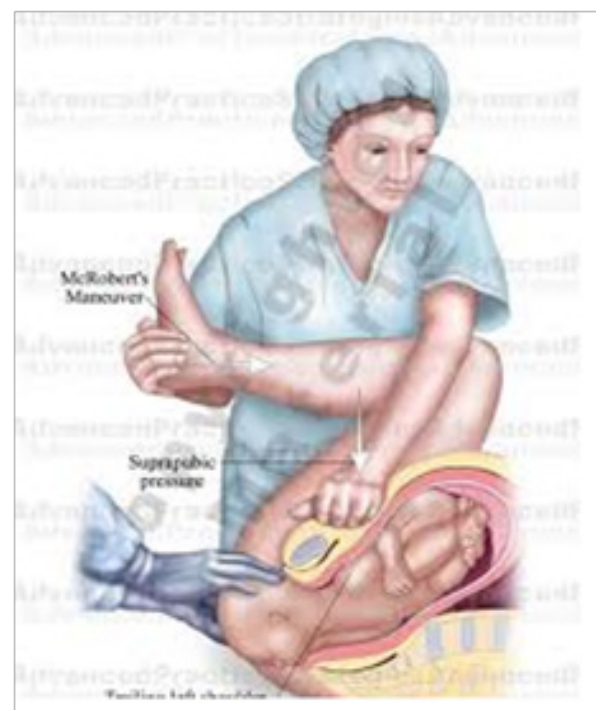

Figure I Somatotopical interpretation on the homunculus model of functionality. ${ }^{16}$

\section{Second-line manoeuvres: I These include}

a) Internal rotation: This is done by giving pressure on the posterior aspect of either the anterior or the posterior shoulder of the fetus. This facilitates adduction of the shoulder and in turn decreases the biacromial diameter. ${ }^{45-48}$

b) All-fours position: ${ }^{40}$ In this type ofmanoeuvre Thesuccess rate is also good. ${ }^{49}$

Third-line manoeuvres: ${ }^{1}$ The maternal morbidity and mortality is high if this type of manoeuvres is not performed by expert hand. .Any of the following can be tried.

a) "The Zavanellimanoeuvre": ${ }^{50}$ Here vaginal delivery is avoided. In this manoeuvreat first the fetalhead is replaced into the vagina and the baby is deliveredby caesarean section..$^{50,51}$

b) "Symphysiotomy":50,51 In this manoeuvrethe anterior fibre of the pubic symphyseal ligaments are dissected. The success rate is also good. ${ }^{52}$

c) "Cleidotomy": This procedure is performed either by surgically or by manually. ${ }^{52}$

\section{Post-partum management of shoulder dystocia}

Documentation should be comprehensive. Specially in keeping birth record the following information are required to look for. ${ }^{53,54}$

i. The time interval between the head and the body of the fetus

ii. The name of the manoeuvres that has been tried, their duration and the outcome.

iii. Clinical findings of the vaginal and perineal examinations

iv. About the amount of bleedings

v. About the team work

vi. Neonatal condition including the Apgar score..$^{53,54}$ 


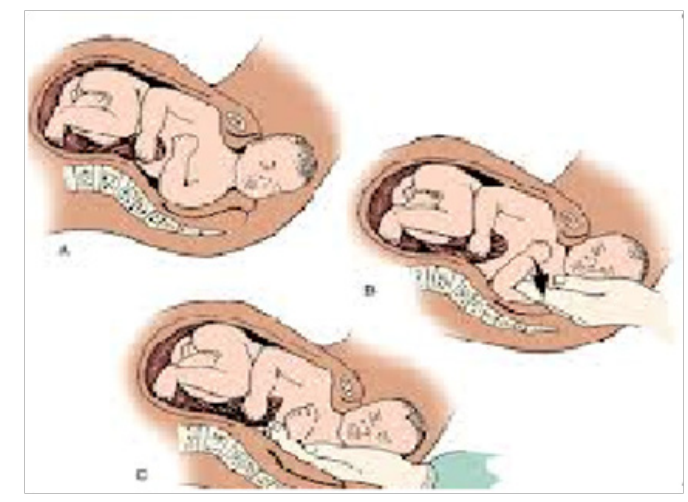

Figure 2 Posterior arm delivery.

\section{Conclusion}

The incidence of the Shoulder dystocia is increasing ${ }^{2}$ due to higher rate of elderly mother and the obesity. Even after managed appropriately there can be significant perinatal mortality and morbidity associated with this condition, ${ }^{55}$ It can be managed systematically. It is frequently associated with permanent birth-related injuries and maternal complications. Calm and effective management of this frightening emergency with applying specified maneuvers will allow a spontaneous delivery of the infant. All healthcare providers attending pregnancies needed to be prepared with a high level of awareness and training to handle vaginal delivery complicated by Shoulder dystocia. $^{56-58}$ All the obstetricians should be prepared to manage this anxiety-provoking emergency. For this reason a team-oriented approach is necessary for the management of SD. For this purpose team-oriented approach is very much important. The key of success lies in managing shoulder dystocia includes constant preparedness, a confident team work and proper documentation. ${ }^{59}$

\section{Acknowledgements}

None.

\section{Conflict of interest}

Author declares that there is no conflict of interest.

\section{References}

1. Royal College of Obstetricians and Gynaecologists. Shoulder dystocia Clinical Green Top Guideline No. 42. London. RCOG. 2005.

2. MacKenzie IZ, Shah M, Lean K, et al. Management of shoulder dystocia trends in incidence and maternal and neonatal morbidity. Obstet Gynecol. 2007;110(5):1059-1068.

3. Gherman RB, Ouzounian JG, Satin AJ, et al. A comparison of shoulder dystocia-associated transient and permanent brachial plexus palsies. Obstet Gynecol. 2003;102(3):544-548.

4. Pondaag W, Allen RH, Malessy MJ. Correlating birthweight with neurological severity of obstetric brachial plexus lesions. BJOG. 2011;118(9):1098-1103.

5. Acker DB, Sachs BP, Friedman EA. Risk factors for shoulder dystocia. Obstet Gynecol. 1985;66(6):762-768.

6. Baskett TF, Allen AC. Perinatal implications of shoulder dystocia. Obstet Gynecol. 1995;86(1):14-27.

7. Woods CE, Westburg NY. A principle of physics as applicable to shoulder dystocia. Am J Obstet Gynecol. 1943;45796-45804.
8. Allen RH. On the mechanical aspects of shoulder dystocia and birth injury. Clin Obstet Gynecol. 2007;50(3):607-623.

9. Smith RB, Lane C, Pearson JF. Shoulder dystocia: what happens at the next delivery?. Br J Obstet Gynaecol. 1994;101(8):713-725.

10. Benedetti TJ, Gabbe SG. Shoulder dystocia. A complication of fetal macrosomia and prolonged second stage of labor with midpelvic delivery. Obstet Gynecol. 1978;52(5):526-529.

11. Acker DB, Sachs BP, Friedman EA. Risk factors for shoulder dystocia. Obstet Gynecol. 1985;66(6):762-768.

12. Cedergren MI. Maternal morbid obesity and the risk of adverse pregnancy outcome. Obstet Gynecol. 2004;103(2):219-224.

13. Mazouni C, Menard JP, Porcu G, et al. Maternal morbidity associated with obstetrical maneuvers in shoulder dystocia. Eur J Obstet Gynecol Reprod Biol. 2006;129(1):15-28.

14. Overland EA, Vatten LJ, Eskild A. Risk of shoulder dystocia: associations with parity and offspring birthweight. A population study of 1914544 deliveries. Acta Obstet Gynecol Scand. 2012;91(4):483-488.

15. Poggi SH, Stallings SP, Ghidini A, et al. Intrapartum risk factors for permanent brachial plexus injury. Am J Obstet Gynecol. 2003;189(3):725-729

16. Gonen O, Rosen DJ, Dolfin Z, et al. Induction of labor versus expectant management in macrosomia: a randomized study. Obstet Gynecol. 2006;89(6):913-917.

17. Dyachenko A, Ciampi A, Fahey J, et al. Prediction of risk for shoulder dystocia with neonatal injury. Am J Obstet Gynecol. 2006;195(6):1544-1549.

18. Nesbitt TS, Gilbert WM, Herrchen B. Shoulder dystocia and associated risk factors with macrosomic infants born in California. Am J Obstet Gynecol. 1998;179(2):476-480.

19. Bahar AM. Risk factors and fetal outcome in cases of shoulder dystocia comparedwith normal deliveries of a similar birthweight. Br J Obstet Gynaecol. 1996;103(9):868-872.

20. Rajan PV, Chung JH, Porto M, et al. Correlation of increased fetal asymmetry with shoulder dystocia in the nondiabetic woman with suspected macrosomia. J Reprod Med. 2009;54(8):478-482.

21. Ouzounian JG, Korst LM, Ahn MO. Shoulder dystocia and neonatal brain injury: Significance of the head-shoulder interval. Am J Obstet Gynecol. 1998:178.

22. Clinical Negligence Sscheme for Trusts. Maternity: Clinical Risk Management Standards. London: NHS Litigation Authority; 2010.

23. Royal College of Obstetricians and Gynaecologists RCOG. Shoulder dystocia. Clinical Green Top Guideline No. 42. London; RCOG. 2005.

24. Gottlieb AG, Galan HL. Shoulder dystocia: an update. Obstet Gynecol Clin N Am. 2007;34(3):501-531.

25. Benjamin K. Part 1. Injuries to brachial plexus: mechanisms of injury and identification of risk factors. Adv Neonatal Care. 2005;5(4):181-189.

26. Gherman RB, Goodwin TM, Souter I, et al. The McRoberts' maneuver for the alleviation of shoulder dystocia: how successful is it?. Am J Obstet Gynecol. 1997;176(3):656-661.

27. Mazouni C, Menard JP, Porcu G, et al. Maternal morbidity associated withobstetrical maneuvers in shoulder dystocia. Eur J Obstet Gynecol Reprod Biol. 2006;129(1):15-18.

28. Diabetes in pregnancy. Management of diabetes and its complications from pre-conception to the postnatal period. Clinical Guideline 63 . London: National Institute for Health and Clinical Excellence; NICE. 2008 . 
29. ACOG Committee on Practice Bulletins. ACOG practice bulletin clinical management guidelines for obstetrician gynecologists. Number 60. Obstet Gynecol. 2005;105(3):675-685.

30. ACOG Committee on Practice Bulletins-Gynecology, The American College of Obstetrician and Gynecologists (2002) ACOG practice bulletin clinical management guidelines for obstetrician gynaecologists. Number 40. Obstet Gynecol. 2002;100(5 Pt 1):1045-1050.

31. Gherman RB. Shoulder dystocia: an evidence-based evaluation of the obstetric nightmare. Clin Obstet Gynecol. 2002;45(2):345-362.

32. Draycott TJ, Crofts JF, Ash JP, et al. Improving neonatal outcome through practicalshoulder dystocia training. Obstet Gynecol. 2008;112(1):14-20.

33. Hope P, Breslin S, Lamont L, et al. Fatal shoulder dystocia:a review of 56 cases reported to the Confidential Enquiry into Stillbirths and Deaths in Infancy. Br J Obstet Gynaecol. 1998;105(12):1256-1261.

34. Focus Group Shoulder Dystocia. In: Confidential Enquiries into Stillbirths and Deaths in Infancy. 5th Annual Report. Maternal and Child Health Research Consortium, London; 1998. p. 73-79.

35. Metaizeau JP, Gayet C, Plenat F. Les Lesions Obstetricales du Plexus Brachial. Chir Pediatr. 1979;20(3):159-163.

36. Hinshaw K. Shoulder dystocia. In: Johanson R, editors. Managing Obstetric Emergencies and Trauma: The MOET Course Manual. London: RCOG Press; 2003. p. 165-174.

37. Stallard TC, Burns B. "Emergency delivery and perimortem C-section". Emerg Med Clin North Am. 2003;21(3):679-693.

38. Kish \& Collea. 2003. 382p.

39. Gonik B, Stringer CA, Held B. An alternate maneuver for management of shoulder dystocia. Am J Obstet Gynecol. 1983;145(7):882-884.

40. Buhimschi CS, Buhimschi IA, Malinow A, et al. Use of McRoberts' position during delivery and increase in pushing efficiency. Lancet. 2001;358(9280):470-471.

41. Gherman RB, Goodwin TM, Ouzounian JG, et al. Spontaneous vaginal delivery: a risk factor for Erb's palsy? Am J Obstet Gynecol. 1998;178(3):423-427.

42. McFarland MB, Langer O, Piper JM, et al. Perinatal outcome and the type and number of maneuvers in shoulder dystocia. Int $J$ Gynaecol Obstet. 1996;55(3):219-224.

43. Lurie S, Ben-Arie A, Hagay Z. The ABC of shoulder dystocia management. Asia Oceania J Obstet Gynaecol. 1994;20(2):195-197.
44. O'Leary JA, Leonetti HB. Shoulder dystocia: prevention and treatment. Am J Obstet Gynecol. 1990;162(1):5-9.

45. Gurewitsch ED, Donithan M, Stallings SP, et al. Episiotomy versus fetal manipulation in managing severe shoulder dystocia: a comparison of outcomes. Am J Obstet Gynecol. 2004;191(3):911-916.

46. Woods CE, Westbury NYA. A principle of physics as applicable to shoulder delivery. Am J Obstet Gynecol. 1943;45(5):796-804.

47. Rubin A. Management of shoulder dystocia. JAMA. 1964;189:835-837.

48. Hinshaw K. Shoulder dystocia. In: Johanson R, Cox C, Grady K, editors. Managing Obstetric Emergencies and Trauma: The MOET Course Manual. London: RCOG Press; 2003. p. 165-174.

49. Bruner JP, Drummond SB, Meenan AL, et al. All-fours maneuver for reducing shoulder dystocia during labor. $J$ Reprod Med. 1998;43(5):439-443.

50. Sandberg EC. The Zavanelli maneuver: a potentially revolutionary method for the resolution of shoulder dystocia. Am J Obstet Gynecol. 1985;152(4):479-484

51. Vaithilingam N, Davies D. Cephalic replacement for shoulder dystocia: three cases. BJOG. 2005;112(5):674-675.

52. Wykes CB, Johnston TA, Paterson-Brown S, et al. Symphysiotomy: a lifesaving procedure. BJOG. 2003;110(2):219-221.

53. Crofts JF, Bartlett C, Ellis D, et al. Documentation of simulated shoulder dystocia: accurate and complete?. BJOG. 2008;115(10):1303-1308.

54. National Health Service Litigation Authority: Summary of sub standard care in cases in brachial plexus injury. NHSLA J. 2003.

55. Gherman RB, Ouzounian JG, Goodwin TM. Obstetric maneuvres for shoulder dystocia and associated fetal morbidity. Am J Obstet Gynecol. 1998;178(6):1126-1130.

56. Gherman RB, Chauhan S, Ouzounian JG, et al. Shoulder dystocia: the unpreventable obstetric emergency with empiric management guidelines. Am J Obstet Gynecol. 2006;195(3):657-672.

57. Mavroforou A, Koumantakis E, Michalodimitrakis E. Physicians liability in obstetric and gynecology practice. Med-Law. 2005;24(1):1-9.

58. Focus Group Shoulder Dystocia. In: Confidential Enquiries into Stillbirths and Deaths in Infancy. 5th Annual Report. Maternal and Child Health Research Consortium, London 1998:73-79.

59. Gottlirb AG, Galan HL. Shoulder dystocia: an update. Obstet Gynecol Clin N Am. 2007;34(3):501-531. 